antología, el más maduro. Su palabra es novedosa y promisoria y su tarea, de hondura.

Todos estos jóvenes forman una promoción novísima a la que no alcanzan las observaciones que hayamos hecho o que hagamos sobre la poesía joven de nuestro país, pero sí les auguramos un futuro magnífico.-Cedomil Goic.

\title{
DAVID H. LAWRENCE, PROFETA DEL AMOR
}

La novela inglesa, en el siglo actual, presenta interesante variedad de matices y originalidad. Es realista con Galsworthy, Bennet y Joyce; romántica con Kipling, Conrad, Chesterton y Wells; psicológica con Katherine Mansfiel y Virginia Wolf; romántica, a veces, y otras realista, con David H. Lawrence y Somerset Maugham. Con el aporte de estos autores, Inglaterra tiene el cuadro más completo de novelistas de Europa. Galsworthy pintó la vida de la clase media acomodada, simbolizada en la familia Forsyte. Bennet, influido por el naturalismo francés, describió la vida de los centros industriales de Stafforshire. Joyce, impresionista, valiéndose del monólogo interior. Kipling evoca el mundo maravilloso de los animales de la selva y la vida no menos maravillosa de esa enmarañada selva humana que es la India. Conrad, polaco nacionalizado, se muestra uno de los mejores intérpretes del carácter inglés, a través de sus novelas de mar, y uno de los grandes estilistas de la lengua inglesa. Chesterton, con gran talento y agresividad, abre rutas nuevas al interés por la Edad Media y la fe cristiana. Wells, basándose en la ciencia, crea mundos fantásticos e imagina mundos utópicos del porvenir. Huxley hace novelas combinando elementos de nuestra compleja cultura actual y Maugham destaca hechos vulgares con tal maestría que parecen extraordinarios, presentando la vida con la objetividad de un lord que mira las cosas con monóculo. Junto a todos ellos, y a muchos otros que no caben en una breve sinopsis, está David H. Lawrence. 
¿Cuál es la importancia de este hombre, cuyos libros fueron un tiempo prohibidos en Gran Bretaña, que ha sido endiosado por muchos y denigrado por otros? Además de ser un buen novelista, Lawrence tiene mucho de profeta. Estudió y dió una solución franca a problemas que atormentaban a su generación: la vida del instinto frente a la inteligencia y la voluntad, y las relaciones entre los sexos. Con esta actitud se echó encima a la mojigatería y al puritanismo. Lawrence es el hombre que proclama la vida del instinto por excima de toda facultad intelectual y el romántico que hace del amor el centro de la existencia humana. Esgrime su pluma contra la hipocresía del puritanismo y aboga por una perfecta armonía entre cuerpo y espíritu.

Su padre, minero, era brusco y despreocupado. Su madre, que provenía de una familia más distinguida, era de sensibilidad delicada y amaba la música, la literatura y las discusiones culturales. Como el padre se dio a la bebida y los trataba con rudeza, la madie terminó por despreciarlo y volcar todo su amor en sus hijos, especialmente en David, que era un muchachito tierno y sensible. David amó a su madre con gran cariño y su muerte, acaecida en 1910, dejó en él huellas profundas. En sus poemas y en su novela Hijos y Amantes podemos comprobar su gran amor por su madre. Hubo en esta época una mujer, Myriam, que influyó en su vida y lo alentó en su carrera literaria, ayudándole a publicar sus poemas. Lawrence la amó, pero se vio obligado a romper con ella debido a su gran timidez y a su amor desmedido por su madre.

Este es el Lawrence de 27 años: sensual y tímido, apasionado y susceptible; llama al amor y lo teme. Pronto encuentra la mujer que, después de su madre, es el centro de su vida: una noble alemana, Frieda von Richthofen. Era esposa de un amigo de Lawrence y tenía tres hijos. Huyó con Lawrence y después de divorciarse casó con él. Frieda mata al puritano Lawrence; le revela las alegrías del amor pagano y la liberación de los instintos, y hace despertar en él ese amor por lo desconocido, por la magia, por lo primitivo y lo sombrío, que penetra toda su obra. En su afán de encontrar ese primiti 
vismo vive en Cornuailles, en Italia, Australia y México. Amó Cornuailles porque le evocaba al Rey Arturo y a Tristán, y porque le parecía encontrarse en el mundo tal como suponía que era en los primeros albores de la civilización celta precristiana, entre una vieja raza aristocrática y extraña que ha creído en las tinieblas y en la magia, y que aún conserva vestigios de la antigua sensibilidad de la noche. Ama y elogia la civilización azteca, cuando está en México, y la civilización etrusca, cuando está en Italia. Siempre está con lo más antiguo, con lo primitivo y original. Cree que el mundo moderno ha substituido al hombre natural, que es el verdaderamente real, por un hombre moderno, que es un ser artificioso, infortunado y $\sin$ equilibrio, porque niega sus instintos, no mantiene vínculos con el universo y reglamenta sus sentimientos con el dinero.

El hombre natural de Lawrence cree más en la magia que en la ciencia, más en la sensibilidad que en la inteligencia, más en los ritos que en los discursos, más en el cuerpo que en el espíritu. Y también escucha al corazón. Esto proclama Lawrence, para liberarse de los excesos de la inteligencia. Pero las danzas y ritos primitivos no son accesibles a todos, menos aún al europeo occidental demasiado civilizado. ¿Cómo se libera, entonces, de la inteligencia? Entregándose a la sensualidad para confundirse con el mundo y lograr esa perfecta armonía entre carne y espíritu que la vida moderna ha roto con su convencionalismo. Y el Lawrence adolescente de carácter tímido y puritano se transforma en el hombre turbulento y seductor, y en el profeta rebelde que augura la disolución del mundo moderno con su puritanismo y el advenimiento de una vida menos artificial y más en armonía con la naturaleza humana.

En resumen, si hubiéramos de definir a Lawrence mencionando cronológicamente los principales aspectos que lo caracterizan, diríamos de él: 1) El adolescente lleno de conflictos. Despreció a su padre, se sintió desgarrado entre su madre y su primera amante, entre el puritanismo y el deseo. A esto debe una gran obra: Hijos $y$ Amantes. 2) Pasa por un cambio de clase, mira a los de arriba con 
mirada serena y ve que son seres que no saben vivir. Encuentra la estimación de sí mismo en un matrimonio sensual y predica al mundo un evangelio de sensualidad. Afirma que sólo es soportable la vida cuando hay una perfecta armonía entre el cuerpo y el espíritu. $\mathrm{Y}$ así Lawrence enseña a los hombres el respeto de sus instintos y sus cuerpos en una época ebria de palabras, conceptos y sistemas. Escribe entonces El amante de lady Chatterley. 3) Contempla el mundo moderno y al hombre moderno y deplora su falta de naturalidad. Predica el retorno a la vida primitiva y sencilla. Y buscando las sociedades primitivas vive en Cornuailles, Australia y México. Ha predicado con el ejemplo, y sus impresiones de estos viajes las ha descrito en forma maestra en su gran obra La serpiente emplumada y en muchos de sus cuentos ("Una mujer partió a caballo, El hombre que amaba las islas", etc.).

Además de las novelas mencionadas, Lawrence escribió, entre otras, El Arco Iris, El hombre que murió, El hombre y el muñeco, El pavón blanco, Mujeres enamoradas, etc. En sus obras, el filósofo se identifica con el artista.

En casi todas sus obras se repite el problema de la armonía, o más bien desarmonía, entre cuerpo y espíritu, el caso de la mujer que se aleja cada vez más del marido que es incapaz de satisfacerla corporal y espiritualmente. En muchas de sus novelas cortas presenta el abismo que a veces separa espiritualmente al hombre y a la mujer.

En el Amante de lady Chatterley el abismo es espiritual y corporal. En El hombre que murió plantea el problema del hombre que ha cumplido una gran misión en la vida, pero que vive desilusionado de la humanidad y que completa su misión con la realización de un amor lleno de ternura. El personaje es Cristo, que no ha muerto con crucifixión y que sale de su tumba al mundo.

Puritano por naturaleza, esgrimió su pluma con fiereza en contra del puritanismo. Amó la vida primitiva y elogió las sombras y la soledad; la soledad que nace de la desilución del hombre ante un mundo limitado y mezquino. Fue aclamado por toda una generación, porque trajo respuestas a problemas que inquietaban a los hombres. 
Filosofía no muy profunda la suya, quizá, pero sí llena de actualidad y expuesta con elocuencia y brillo.-Ramiro Páez.

Un clásico peruano recién nacido: "LA FuGA", de Alberto Wagner de Reyna

La Fuga es una novela que, tomándola como tal, se nos escapa. El género está ya sobradamente definicio para que no se le resista el lector a las primeras páginas. ¿La Fuga no lo devora, ni se deja devorar por él? Entonces el autor ha periclitado. ¿Dónde están los lances concretos, palpitantes, la sucesión contrapuntística de hechos y peripecias? Después de todo, argüirá el más avisado, Wagner era un místico, un existencialista heideggeriano, un filósofo, en fin. Y de allí que lo sorprendamos divagando, sin atracar la entraña de su asunto. No es una novela, proclamará dueño de sí, algún despabilado, huyendo, acaso, de La Fuga...

Y se perderá irremediablemente, si no es capaz de reaccionar a tiempo contra el prejuicio poderoso, algo mejor y más interesante que una novela: un extraordinario libro.

Desde luego, es una novela, aunque se evada de los cánones clásicos, consagrados e inconmovibles, aún en Virginia Woolf, aún en Joyce, es una novela, con una técnica inobjetable, mágica, bergsoniana, cinematográfica. Pero es también muchas otras cosas, a cual más suculenta. Y entre esas otras cosas está el de ser, sencillamente, un gran libro, algo que no alcanzan, por regla general, a ser las novelas de más éxito. Un libro, un todo, un alma, un espíritu. Hombre, vida, muerte, pensamiento, fe, destino, historia, están vigorosamente presentes. Los estructura la filosofía, la reflexión humanística, el humorismo, la greguería, la sátira, la poesía, el ensayo, la sociología política. Todo un universo en pie.

Pero hay a su vez otro elemento imponderable, que funde en una gran unidad todo este material heterogéneo, objetivo y subjetivo, y es el lenguaje, exaltado hasta aquella dimensión literaria que le 